\title{
Uranium sorption onto mullite: Characteristics of isotherms, kinetics and thermodynamics
}

\author{
Liao Rong $^{1}$, Shi Zeming ${ }^{1,2, *} \mathbb{0}$, Hou Yun $^{1}$, Zhang Kailiang ${ }^{1}$, Zhang Junji ${ }^{1}$, \\ Wang Xinyu ${ }^{1,2}$, Cheng $\mathrm{KE}^{1}$ and Yang Lvhang ${ }^{1}$ \\ ${ }^{1}$ College of Geoscience, Chengdu University of Technology, Chengdu 610 059, People's Republic of China. \\ 2 Applied Nuclear Techniques in Geosciences Key Laboratory of Sichuan Province, Chengdu 610059 , \\ People's Republic of China. \\ *Corresponding author.e-mail: shizm@cdut.edu.cn
}

MS received 29 May 2018; revised 1 September 2018; accepted 29 April 2019; published online 21 June 2019

The sorption of uranium onto mullite influenced by $\mathrm{pH}$, initial adsorbate concentration, sorption dose and reaction duration was probed utilising batch techniques. X-ray powder diffraction was used to characterise mullite. Sorption isotherms, sorption kinetics and thermodynamic characteristics were also investigated. The Freundlich isotherm model could best depict experimental data, suggesting that the sorption mechanism of uranium onto mullite may be multi-layer adsorption. The $E$ value obtained from the Dubinin-Radushkevich model implied that uranium sorption onto mullite is a chemical process. The pseudo-second-order model successfully depicted uranium sorption onto mullite, indicating that the sorption rate is mainly controlled by chemical sorption. The thermodynamic parameters computed showed that entropy and enthalpy under the trial conditions were positive and that values of $\Delta G^{\Theta}$ were negative. Thermodynamics illustrated that the sorption process was endothermic and spontaneous. The results achieved in this study are intended to further a deeper comprehension of uranium migration in silicate minerals.

Keywords. Uranium; mullite; isotherm; kinetic; thermodynamics.

\section{Introduction}

With the continual importance of the nuclear industry, the radionuclide uranium, part of the indispensable raw stocks of the nuclear industry, has brought enormous energy to the world. However, the use of uranium has also produced a large amount of radioactive waste, for instance, exhaust gas, liquid waste and off scum caused by reactor operations, uranium smelting and nuclear weapons manufacturing (Monnet et al. 2017). Once radioactive contaminants are released into the environment, such actions as enrichment, activation and migration of uranium can do serious harm to water, soil, animals, plants, etc. Because of the characteristics of long-term accumulation, concealment and lag, research on and remediation techniques for radioactive contamination have always attracted attention from the whole world (Sylwester et al. 2000). Sorption is more widely used for heavy metal pollution remediation than membrane separation, precipitation, ion exchange and extraction (Michard et al. 1996; Ganesh et al. 1999; Vaaramaa et al. 2000; Kulkarni 2003; Singh et al. 2010). At present, research on the sorption of uranium onto silicate minerals is chiefly concentrated on clay minerals such as kaolinite, illite, montmorillonite and bentonite (Chisholm-Brause et al. 2001; Ren 
et al. 2010; Du et al. 2015; Reinoso-Maset and Ly 2016). However, the sorption characteristics of uranium onto mullite have not been commonly studied. Mullite is considered the unique steady compound in the $\mathrm{Al}_{2} \mathrm{O}_{3}-\mathrm{SiO}_{2}$ binary system, and the composition of mullite is ordinarily regarded as a solid solution series (Zhao et al. 2006). Its most common compositions are $3 \mathrm{~A}_{2} \mathrm{O}_{3} \cdot 2 \mathrm{SiO}_{2}$ and $2 \mathrm{~A}_{2} \mathrm{O}_{3} \cdot \mathrm{SiO}_{2}$ (Rüscher 1996; Freimann and Rahman 2001; Voll et al. 2001; Griesser et al. 2008). Because of the high thermostabilisation, low thermal dilation, high creep resistance and corrosion stability of mullite (Schneider et al. 2008), research on mullite has become deeper and is applied in many directions. The study of porous mullite ceramics shows that the material has a large specific surface (Suzuki et al. 2001). The research on and production of nano-mullite ceramic membranes shows that they have the characteristics of large specific surface and multiple apertures (Huang et al. 1998). The heating rate has an impact on mullite formation from a kaolin raw material (Castelein et al. 2001). As one of the silicate minerals, mullite is widely used in the fields of chemical, biological, and electric applications, national defence and environmental protection. Studies have shown that mullite can be abundant in fly ash (Vassilev et al. 2003). The mullite in fly ash mainly comes from the decomposition products of other clay minerals such as calcined kaolinite and illite. In China, fly ash is used as an adsorbent in reducing heavy metal pollution. Lima et al. (2012) assessed the remediation and stabilisation of heavy metals by fly ash. Li et al. (2013) studied the efficiency of adsorption of wastewater containing uranium by fly ash. However, the role of mullite as one of the crystalline mineral components in fly ash in the process of treatment for wastewatercontaining uranium by fly ash is still unclear. Therefore, the study of the adsorption of uranium on mullite not only can determine the adsorption capacity of mullite itself but also can help to better understand the role of mullite in the reduction of radioactive environmental pollution by fly ash. In addition, comparing changes in the mineral adsorption capacity of clay minerals such as kaolinite and illite before and after high-temperature calcination and decomposition is also helpful to understand the optimal adsorption capacity of silicate minerals.

Accordingly, the sorption characteristics of uranium on mullite are studied by the static experimental method in this paper. X-ray powder diffraction (XRD) is utilised to characterise mullite. The objectives are to assess the influence of diverse environmental parameters on uranium sorption onto mullite, including $\mathrm{pH}$, initial adsorbate concentration, sorption dose and duration of the reaction, and to study sorption kinetics, sorption isotherms and thermodynamics for the possible mechanism of sorption of uranium onto mullite. This paper is expected to contribute to comprehending the migration of uranium in silicate minerals and establishing some connection between kaolinite sorption and mullite sorption.

\section{Materials and methods}

\subsection{Materials}

Uranyl standard solution $\mathrm{UO}_{2}\left(\mathrm{NO}_{3}\right)_{2} \cdot 6 \mathrm{H}_{2} \mathrm{O}$ (ICPMass Pure Grade) was acquired from Inorganic Ventures, Christiansburg, Virginia. The mullite sample was derived from Tianjin province (China). XRD was utilised to analyse mullite. XRD spectra were recorded at $2 \theta$ values from $5^{\circ}$ to $80^{\circ}$ on an Ultima IV X-ray diffractometer (Rigaku) with a D/teX Ultra detector. The X-ray beam was Ni-filtered $\mathrm{Cu} \mathrm{K \alpha}$ radiation $(\lambda=0.154 \mathrm{~nm})$ operated at $40 \mathrm{kV}$ and $40 \mathrm{~mA}$ with a step of $15^{\circ} / \mathrm{min}$. All chemicals and reagents utilised during the experiments were bought as analytically pure without any refinement process. The experimental water was distilled water.

\subsection{Sorption experiments}

A batch equilibrium experiment progressed at different temperatures in $50 \mathrm{ml}$ polypropylene centrifuge tubes, and samples were analysed in triplicate. $\mathrm{HCl}$ and $\mathrm{NaOH}(1 \mathrm{~mol} / \mathrm{l})$ solutions were utilised to adjust $\mathrm{pH}$ values daily to the desired $\mathrm{pH}$ level. The expected solid-to-solution ratio (SSR) was set to $10 \mathrm{~g} / \mathrm{l}$, so $0.4 \mathrm{~g}$ of mullite and $40 \mathrm{ml}$ of uranium solution were placed in tubes. Then, the oscillation time of the sample on the thermostatic oscillator was set to $48 \mathrm{~h}$ to provide enough time to attain reaction equilibrium in a given experimental environment. After vibration, samples were centrifuged at $3500 \mathrm{rpm}$ for $20 \mathrm{~min}$. For determination of the dissolved uranium concentration, $10 \mathrm{ml}$ of filtered supernatant was collected. An inductively coupled plasma mass spectrometer was utilised to analyse uranium concentration immediately.

The amount of uranium sorption onto mullite was computed by the disparity between the initial 
and equilibrium concentrations. The sorption capacity of uranium onto mullite $\left(Q_{\mathrm{e}}, \mathrm{mg} / \mathrm{g}\right)$ and the sorption rate $(R, \%)$ were computed utilising the following equations:

$$
\begin{gathered}
Q_{\mathrm{e}}=\frac{\left(C_{0}-C_{\mathrm{e}}\right) V_{\mathrm{s}}}{m}, \\
R=\left(1-C_{\mathrm{e}}\right) / C_{0} \times 100 \%,
\end{gathered}
$$

where $C_{0}(\mathrm{mg} / \mathrm{l})$ is the original concentration of uranium in solution, $C_{\mathrm{e}}(\mathrm{mg} / \mathrm{l})$ is the uranium concentration in solution at equilibrium, $m(\mathrm{~g})$ is the weight of mullite and $V_{\mathrm{s}}(\mathrm{ml})$ is the bulk of the solution.

\section{Results}

\subsection{Characterisation of mullite with XRD}

As shown in figure 1, the peaks in the XRD pattern of mullite labelled with $Q$ is the characteristic peak of quartz, which is an impurity in the sample, and the mullite peaks are labelled with $M$. The characteristic peak at $21.2^{\circ}$ is in accordance with quartz. The peaks at $15.7^{\circ}, 25.6^{\circ}, 32.7^{\circ}, 34.7^{\circ}$ and $40.3^{\circ}$ are matched with mullite by comparison with the spectrum of mullite on an X-ray diffraction standard card.

\subsection{Uranium sorption onto mullite influenced by $p H$}

The solution $\mathrm{pH}$ is one of the foremost variables impacting uranium sorption onto mullite. Figure 2 shows that the amounts of adsorbed uranium increased with increasing $\mathrm{pH}$ values until $\mathrm{pH} 7$. The amount of sorption was the strongest at $\mathrm{pH} 7$.

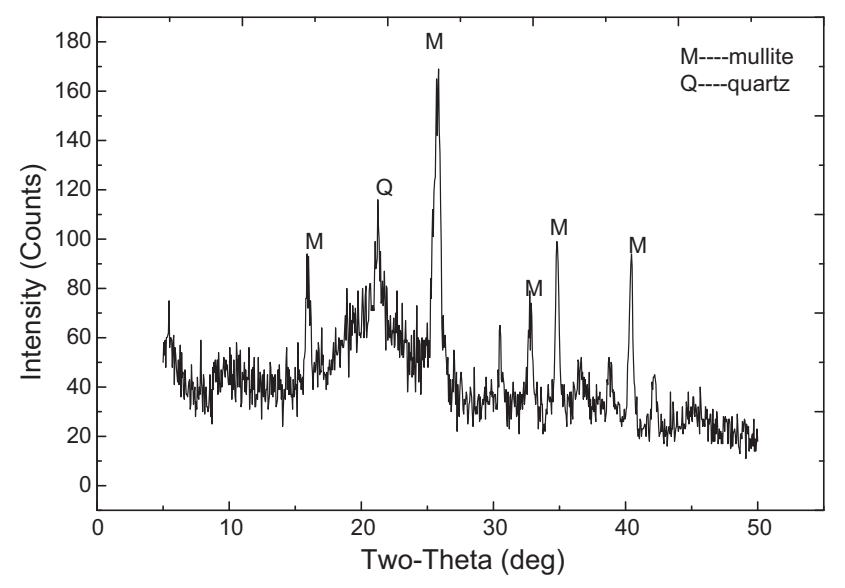

Figure 1. X-ray diffraction pattern of mullite.

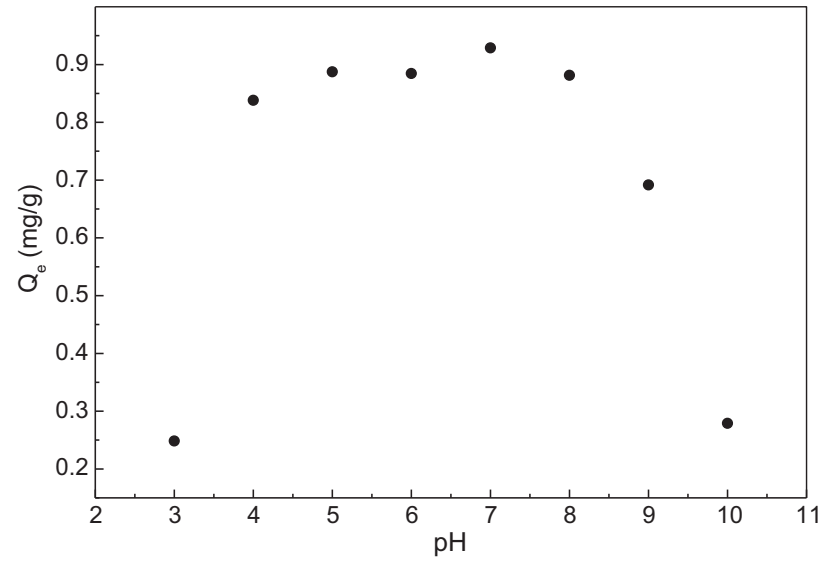

Figure 2. Uranium sorption onto mullite influenced by $\mathrm{pH}$ $\left(C_{0}=10 \mathrm{mg} / \mathrm{l}\right.$, temperature $25^{\circ} \mathrm{C}$, contact time $48 \mathrm{~h}$ and SSR $10 \mathrm{~g} / \mathrm{l})$.

Above $\mathrm{pH} 7$, the sorption capacity of uranium weakened with increasing $\mathrm{pH}$ values. At low $\mathrm{pH}$ values (1-4), $\mathrm{UO}_{2}{ }^{2+}$ ions are the main form of uranium (Cumberland et al. 2016), and the excess $\mathrm{H}^{+}$ions compete with $\mathrm{UO}_{2}{ }^{2+}$ ions to occupy active sites on the mullite surface. Meanwhile, the charge of mullite is positive because of the $\mathrm{H}^{+}$ions adsorbed on the mullite surface, which excludes $\mathrm{UO}_{2}{ }^{2+}$ ions with their positive charge. Hence, sorption efficiency is low at lower $\mathrm{pH}$ values. However, at higher $\mathrm{pH}$ values (4-9), $\mathrm{UO}_{2} \mathrm{OH}^{+}$, $\left(\mathrm{UO}_{2}\right)_{2}(\mathrm{OH})_{2}^{2+},\left(\mathrm{UO}_{2}\right)_{3}(\mathrm{OH})^{5+}$ and $\mathrm{UO}_{2}$ are the predominant uranium species in solution (Cumberland et al. 2016), and these species are available for sorption onto mullite, resulting in an increase in the sorption of uranium. The polymerisation of the hydrolysed uranyl species that have low adsorption affinity under highly alkaline conditions, including $\mathrm{UO}_{2}(\mathrm{OH})_{4}^{2-}$ and $\mathrm{UO}_{2}(\mathrm{OH})_{5}^{3-}$ (Clark et al. 1999), induces repulsion between uranium and mullite.

\subsection{Uranium sorption onto mullite influenced by the $S S R$}

As shown in figure 3, under the condition that the initial concentration of the adsorbent uranium remains unchanged, an increase in mullite provides more active sites for adsorption, which is conducive to ion exchange adsorption and the formation of complexes of uranium in mullite, thus reducing the uranium concentration in the solution, increasing the uranium concentration on mullite and increasing the adsorption rate (Zhu et al. 2011). However, as the volume and uranium concentration in the adsorption system remain unchanged, the dispersion degree between mullite particles 


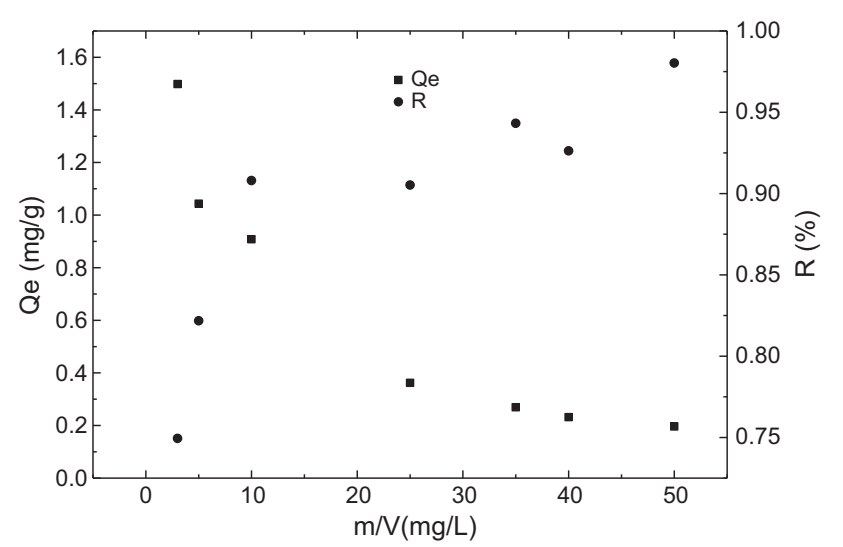

Figure 3. Uranium sorption onto mullite influenced by SSR $\left(C_{0}=10 \mathrm{mg} / \mathrm{l}\right.$, temperature $25^{\circ} \mathrm{C}$, contact time $48 \mathrm{~h}$ and $\mathrm{pH}$ $5.37 \pm 0.5)$.

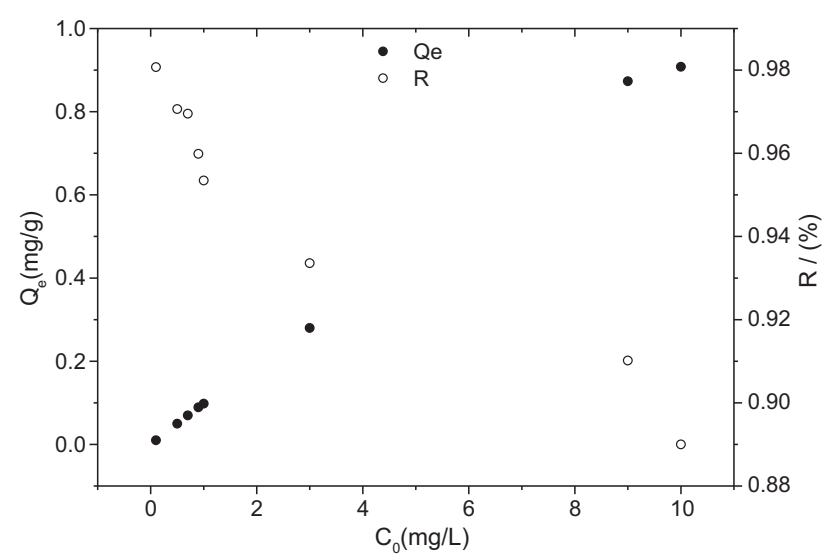

Figure 4. Uranium equilibrium uptake behaviour with varying initial uranium concentrations (SSR $10 \mathrm{~g} / \mathrm{l}$, temperature $25^{\circ} \mathrm{C}$, contact time $48 \mathrm{~h}$ and $\left.\mathrm{pH} 5.37 \pm 0.5\right)$.

decreases with increasing solid-liquid ratio, and the aggregation phenomenon occurs, which reduces the specific surface area of the adsorbent. With the increase in mullite, the increased adsorption activity sites are in an unsaturated state, thus reducing the adsorption amount of mullite per unit mass (Fatima et al. 2013).

\subsection{Uranium sorption at different initial adsorbate concentrations}

The change in uranium sorption capacity onto mullite with the initial adsorbate concentration is displayed in figure 4. With an increase in the original concentration of uranium, the amount of sorption onto mullite increases, but the sorption rate decreases. This result could be attributed to the higher interaction between uranium and mullite (Crawford et al. 2017). When the concentration of uranium is very low, the sorption rate is very high because of the large number of unsaturated ionic groups and multiple apertures in mullite, which can quickly adsorb uranium and exchange ions. However, with the increase and overabundance of uranium, the unsaturated ionic groups of mullite become saturated, and ion exchange tends to balance. Therefore, excess uranium is in the state of free hydrated ions, resulting in a reduction of the adsorption rate.

\subsection{Sorption isotherms of uranium onto mullite}

To study the distribution of uranium onto the mullite surface and deduce the molecular state and adsorption layer structure of the interface better when the system is in equilibrium, sorption isotherms are imperative (Aytas et al. 2009). The adsorption equilibrium constants that are calculated by the suitable isotherm equations describing the sorption process are related to the adsorption mechanism and the structure of the adsorbent.

The fitting correlation of the curve at the equilibrium state can help to reveal the adsorption mechanism. Figure 5 displays the sorption isotherm of mullite. The three models utilised to fit the experimental data are the Langmuir, Freundlich and Dubinin-Radushkevich (D-R) isothermal models. The following equations describe these isotherm models (Gao et al. 2017).

The linear equation for Langmuir isothermal sorption is

$$
\frac{C_{\mathrm{e}}}{Q_{\mathrm{e}}}=\frac{1}{b_{1} Q_{\mathrm{ml}}}+\frac{C_{\mathrm{e}}}{Q_{\mathrm{ml}}} .
$$

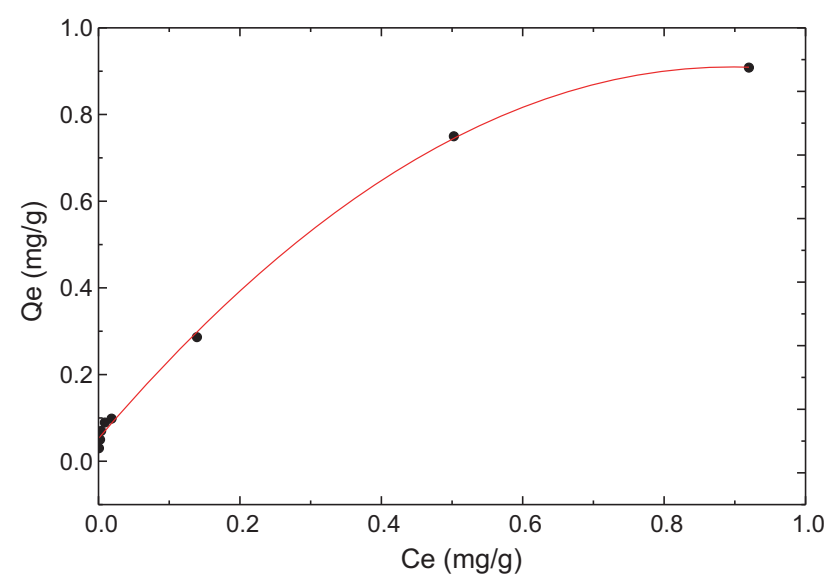

Figure 5. Sorption isotherm of uranium onto mullite. 
The linear equation for Freundlich isothermal sorption is

$$
\ln Q_{\mathrm{e}}=\ln K_{\mathrm{f}}+(1 / n) \ln C_{\mathrm{e}} .
$$

The linear equation for $\mathrm{D}-\mathrm{R}$ isothermal sorption is

$$
\ln Q_{\mathrm{e}}=\ln Q_{\mathrm{md}}-\beta \varepsilon^{2},
$$

where $Q_{\mathrm{ml}}$ and $Q_{\mathrm{md}}(\mathrm{mg} / \mathrm{g})$ are the theoretical monolayer sorption powers for the Langmuir and D-R isothermal models, respectively; $b_{1}(1 / \mathrm{mg})$ is the Langmuir equilibrium constant; $K_{\mathrm{f}}(\mathrm{mg} / \mathrm{g})$ is the Freundlich constant denoting absorptivity; $n$ $(\mathrm{mg} / \mathrm{l})$ is an empirical coefficient related to the sorption intensity; and $\beta$ is the activity coefficient related to the average sorption energy expressed by the letter $E$. In addition, $\varepsilon$ expresses the Polanyi adsorption potential, and its equation is

$$
\varepsilon=\mathrm{RT} \ln \left(1+\frac{1}{C_{\mathrm{e}}}\right),
$$

where $R(8.314 \mathrm{~J} / \mathrm{mol} \mathrm{K})$ is the ideal gas constant and $T(\mathrm{~K})$ is the Kelvin temperature.

When the $E$ value is between 1 and $8 \mathrm{~kJ} / \mathrm{mol}$, the sorption process is physical, and when the $E$ value is between 8 and $16 \mathrm{~kJ} / \mathrm{mol}$, the sorption mechanism is chemical (Zheng et al. 2009). The $E$ value can be computed according to $\beta$ with the following equation:

$$
E=\frac{1}{\sqrt{-2 \beta}} .
$$

The parameters obtained by fitting the data with the three models are shown in table 1.

Uranium sorption onto mullite can be depicted more appropriately by the Freundlich isotherm model than by the Langmuir isotherm model given the more perfect correlation coefficient $\left(R^{2}>0.99\right)$ of the former, pointing out that uranium sorption onto mullite is possibly a multi-layer sorption process and that the surface of the mullite is inhomogeneous. The $n$ value greater than 1 for the Freundlich model suggests advantageous sorption conditions (Aytas et al. 2009).
The value $E$ is computed by the intercept and slope from the linear plot of $\ln Q_{\mathrm{e}} v s . \varepsilon^{2}$ (figure 6) according to equation (7). As shown in table 1 , the $E$ value $(15.81 \mathrm{~kJ} / \mathrm{mol})$ lies between 8 and $16 \mathrm{k} \mathrm{J} / \mathrm{mol}$, indicating that the sorption process of uranium onto mullite is essentially chemical.

\subsection{Sorption kinetics of uranium onto mullite}

Sorption kinetics can effectively reflect the diffusion and rate of sorption ( $\mathrm{Pu}$ et al. 2013). Figure 7 shows that uranium sorption onto mullite is relatively rapid within $10 \mathrm{~h}$. Because sorption was equilibrated after $20 \mathrm{~h}, 48 \mathrm{~h}$ was identified as the connect time for uranium sorption onto mullite for the experimental reaction equilibrium (Nekhunguni et al. 2017).

For an in-depth comprehension of the latent adsorption rate change and adsorption mechanisms, two models utilised to fit the data were pseudo-first-order and pseudo-second-order kinetic models (Mellah et al. 2006). The kinetic features of uranium sorption onto mullite can be comprehended from these models. The two equations can be expressed as equations ( 8 and 9 ).

The pseudo-first-order equation is

$$
\ln \left(Q_{\mathrm{e}}-Q_{\mathrm{t}}\right)=\ln Q_{\mathrm{e}}-K_{1} t .
$$

\begin{tabular}{|c|c|c|c|c|c|c|c|c|}
\hline \multirow[b]{2}{*}{$\begin{array}{l}T \\
(\mathrm{~K}) \\
\end{array}$} & \multicolumn{3}{|c|}{ Langmuir isothermal model } & \multicolumn{3}{|c|}{ Freundlich isothermal model } & \multicolumn{2}{|c|}{$\mathrm{D}-\mathrm{R}$ isothermal model } \\
\hline & $\begin{array}{c}b \\
(\mathrm{l} / \mathrm{g})\end{array}$ & $R^{2}$ & $\begin{array}{c}Q_{\max } \\
(\mathrm{mg} / \mathrm{g})\end{array}$ & $\begin{array}{c}n \\
(\mathrm{l} / \mathrm{g})\end{array}$ & $R^{2}$ & $\begin{array}{c}K_{\mathrm{f}} \\
(\mu \mathrm{g} / \mathrm{g})\end{array}$ & $\begin{array}{c}E \\
(\mathrm{~kJ} / \mathrm{mol})\end{array}$ & $R^{2}$ \\
\hline 298 & 8.79 & 0.92 & 0.99 & 2.10 & 0.99 & 0.64 & 15.81 & 0.97 \\
\hline
\end{tabular}

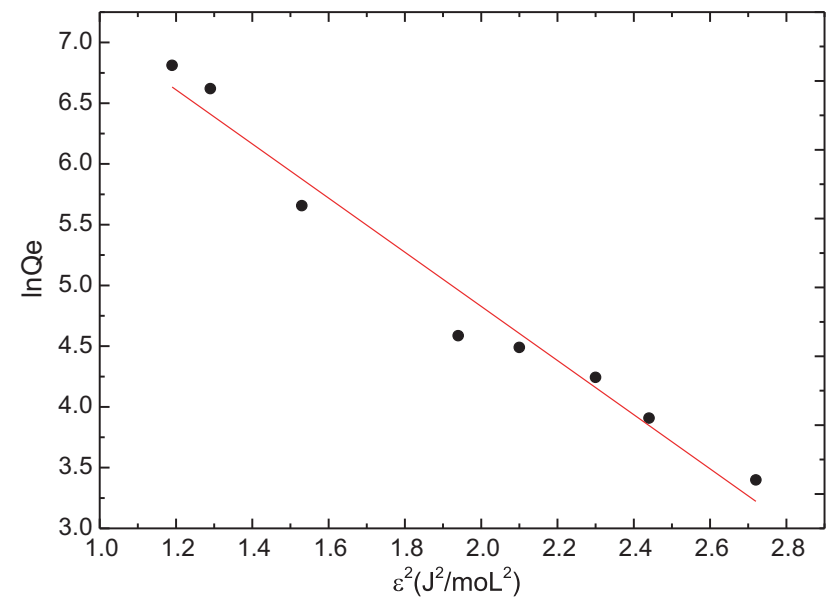

Figure 6. D-R sorption isotherm of uranium onto mullite.

Table 1. Results for the sorption isotherm of uranium adsorption onto mullite. 
The pseudo-second-order equation is

$$
\frac{t}{Q_{\mathrm{t}}}=\frac{1}{K_{2} Q_{\mathrm{e}}^{2}}+\frac{t}{Q_{\mathrm{e}}}
$$

where $K_{1}(\mathrm{~g} / \mathrm{mg} \mathrm{h})$ is the rate constant for the pseudo-first-order equation; $K_{2}(\mathrm{~g} / \mathrm{mg} \mathrm{h})$ is the rate constant for the pseudo-second-order equation and $Q_{\mathrm{t}}(\mathrm{mg} / \mathrm{g})$ is the sorption capacity of mullite at time $t(\mathrm{~h})$.

The determination coefficient $\left(R^{2}\right)$ can reveal the ability of a kinetic model equation to depict the sorption mechanism of uranium onto mullite. In table 2, the kinetic parameters are displayed. The pseudo-second-order kinetic model can depict the uranium sorption process onto mullite more suitably than the pseudo-first-order kinetic model based on the more perfect correlation coefficient of the former, indicating that the pseudo-second-order kinetic model can preferentially reflect the adsorption mechanism and that the sorption process is primarily chemical (Ding et al. 2014). The value of $Q_{\max }$ from the experiment is approximate. The results conform to the analysis results for the average free energy $E$ above.

\subsection{Sorption thermodynamics}

Deeper information about internal energy changes associated with the sorption process of uranium

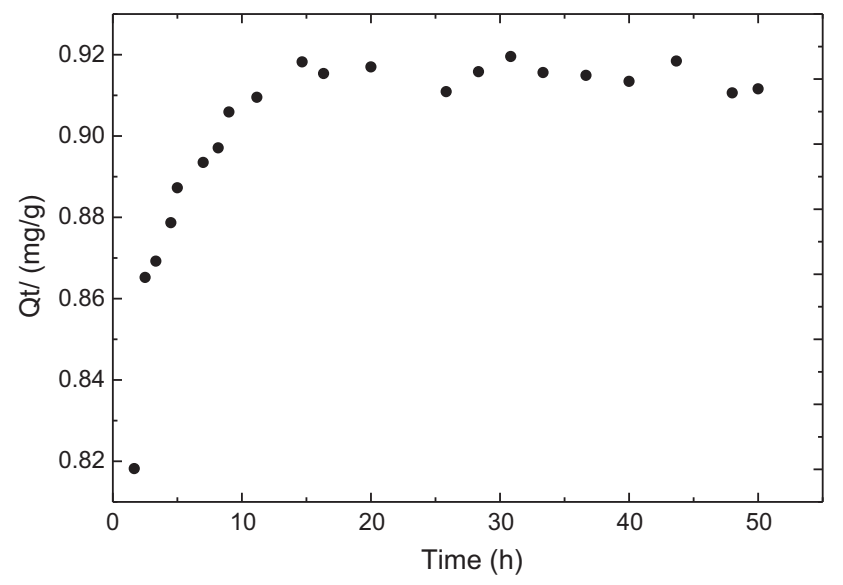

Figure 7. Uranium sorption onto mullite influenced by contact time $\left(C_{0}=10 \mathrm{mg} / \mathrm{l}\right.$, SSR $10 \mathrm{~g} / \mathrm{l}$, temperature $25^{\circ} \mathrm{C}$, contact time $48 \mathrm{~h}$ and $\mathrm{pH} 5.37 \pm 0.5)$. onto mullite can be obtained after a thermodynamic investigation. The parameters for the thermodynamic study can be computed utilising the three equations below ( $\mathrm{Pu}$ et al. 2013):

$$
\begin{gathered}
K_{\mathrm{D}}=\frac{Q_{\mathrm{e}}}{C_{\mathrm{e}}}, \\
\ln K_{\mathrm{D}}=\frac{\Delta S^{\Theta}}{R}-\frac{\Delta H^{\Theta}}{R T}, \\
\Delta G^{\Theta}=\Delta H^{\Theta}-T \Delta S^{\Theta},
\end{gathered}
$$

where $K_{\mathrm{D}}(\mathrm{ml} / \mathrm{g})$ is the sorption equilibrium constant. $\Delta H^{\Theta}$ and $\Delta S^{\Theta}$ can be obtained by the intercept and slope, respectively, from the linear plot of $\ln K_{\mathrm{D}}$ vs. 1/T (figure 8) on the basis of equation (11). Variations in the Gibbs energy are expressed by $\Delta G^{\Theta} . \Delta H^{\Theta}$ and $\Delta S^{\Theta}$ are the values of enthalpy and entropy variations, respectively.

After computing the experimental data at five different temperatures $(298 \pm 1,308 \pm 1,313 \pm 1$, $318 \pm 1$, and $323 \pm 1 \mathrm{~K}$ ), the thermodynamic parameters shown in table 3 were obtained. The $\Delta H^{\Theta}$ value is positive, indicating that the sorption process of uranium onto mullite is endothermic. This feature may be due to the energy needed for baring the hydration sheath of uranium dissolved in an aqueous solution before sorption onto mullite.

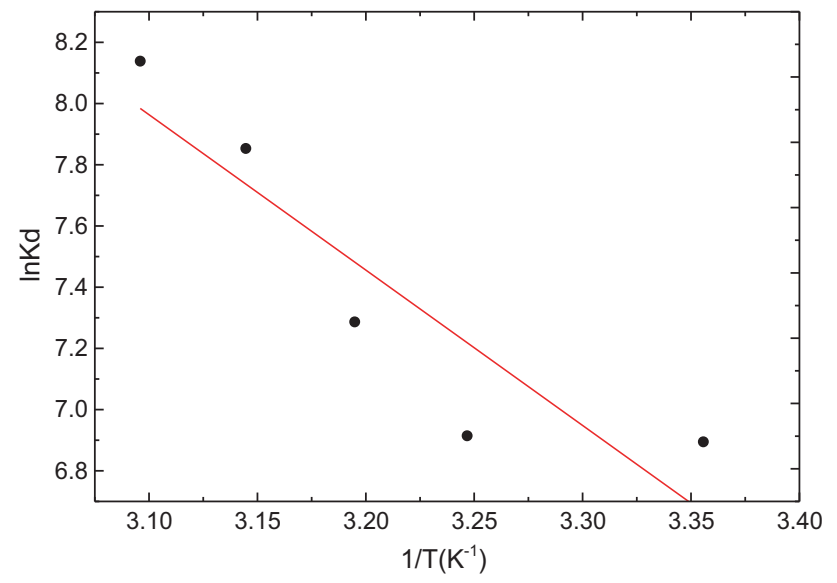

Figure 8. Linear plots of $\ln K_{\mathrm{D}}$ vs. $1 / T\left(C_{0}=10 \mathrm{mg} / \mathrm{l}\right.$, SSR $0.4 \mathrm{~g} / 40 \mathrm{ml}$, temperature $25^{\circ} \mathrm{C}$, contact time $48 \mathrm{~h}$ and $\mathrm{pH}$ $5.37 \pm 0.5)$.

Table 2. Parameters for the kinetics of uranium sorption onto mullite.

\begin{tabular}{lcccccc}
\hline \multicolumn{2}{ll}{ Pseudo-first-order model } & & & \multicolumn{3}{c}{ Pseudo-second-order model } \\
\cline { 1 - 2 } \cline { 5 - 7 } $\begin{array}{l}K_{1} \\
(\mathrm{~g} / \mathrm{mg} \mathrm{h})\end{array}$ & $\begin{array}{c}Q_{\mathrm{e}} \\
(\mathrm{mg} / \mathrm{g})\end{array}$ & $R^{2}$ & & $\begin{array}{c}K_{2} \\
(\mathrm{~g} / \mathrm{mg} \mathrm{h})\end{array}$ & $\begin{array}{c}Q_{\mathrm{e}} \\
(\mathrm{mg} / \mathrm{g})\end{array}$ & $R^{2}$ \\
\hline 0.05 & 6.77 & 0.85 & & 3.38 & 0.94 & 0.99 \\
\hline
\end{tabular}


Table 3. Parameters for the thermodynamics of uranium sorption onto mullite.

\begin{tabular}{lccccccc}
\hline$C_{0}$ & $\Delta H^{\Theta}$ & $\Delta S^{\Theta}$ & \multicolumn{5}{c}{$\Delta G^{\Theta}(\mathrm{kJ} / \mathrm{mol})$} \\
\cline { 3 - 8 }$(\mathrm{mg} / \mathrm{l})$ & $(\mathrm{kJ} / \mathrm{mol})$ & $(\mathrm{kJ} / \mathrm{mol} \mathrm{K})$ & $298 \pm 1 \mathrm{~K}$ & $308 \pm 1 \mathrm{~K}$ & $313 \pm 1 \mathrm{~K}$ & $318 \pm 1 \mathrm{~K}$ & $323 \pm 1 \mathrm{~K}$ \\
\hline 10 & 42.21 & 82.20 & -24.45 & -25.28 & -25.68 & -26.10 & -26.51 \\
\hline
\end{tabular}

Uranium usually exists as hydrated ions in aqueous solutions, and this process requires energy. The value of $\Delta S^{\Theta}$ is positive, corresponding to an enhanced free degree of the adsorbed substance. $\Delta G^{\Theta}$ values are all negative under the experimental conditions, indicating that the sorption process is spontaneous. The $\left|\Delta G^{\Theta}\right|$ value increases with higher temperature, suggesting that higher temperature is beneficial to the sorption (Gao et al. 2017). Most likely, this effect is a result of uranium desolvation and reduction of the boundary layer thickness of the mullite surface. Another reason may be the growth of active sites that can be utilised for sorption (Aytas et al. 2009).

\section{Conclusions}

The sorption of uranium onto mullite depended on $\mathrm{pH}$ and was fitted successfully by the Freundlich model, indicating that the sorption mechanism was probably monolayer adsorption. The sorption of uranium onto mullite was rapid, reaching a state of equilibrium after $20 \mathrm{~h}$. The kinetic parameters indicated that the sorption of uranium onto mullite was fitted suitably with a pseudosecond-order kinetic model. The $E$ value indicated that the sorption of uranium onto mullite was chemical. Thermodynamic parameters signified that higher temperature was beneficial to the sorption. The negative $\Delta G^{\Theta}$ values showed that the process for sorption onto mullite was feasible and spontaneous.

\section{Acknowledgements}

The comments and suggestions of the responsible editors and reviewers during the submission and review of this paper are always appreciated by our team. The National Natural Science Foundation of China (No. 41373120) and the Ministry of Environmental Protection of China (No. 201509024) sustained this research with financial support.

\section{References}

Aytas S, Yurtlu M and Donat R 2009 Adsorption characteristic of $\mathrm{U}(\mathrm{VI})$ ion onto thermally activated bentonite; J. Hazards Mater. 172(2-3) 667-674, https://doi.org/10. 1016/j.jhazmat.2009.07.049.

Castelein O, Soulestin B, Bonnet J P and Blanchart P 2001 The influence of heating rate on the thermal behaviour and mullite formation from a kaolin raw material; Ceram. Int. 27(5) 517-522, https://doi.org/10.1016/S0272-8842(00)00 110-3.

Chisholm-Brause C J, Berg J M, Matzner R A and Morris D E 2001 Uranium(VI) sorption complexes on montmorillonite as a function of solution chemistry; J. Colloid Interface Sci. 233(1) 38-49, https://doi.org/10.1006/jcis.2000.7227.

Clark D L, Conradson S D, Donohoe R J, Keogh D W, Morris D E, Palmer P D, Rogers R D and Tait C D 1999 Chemical speciation of the uranyl ion under highly alkaline conditions. Synthesis, structures, and oxo ligand exchange dynamics; Inorg. Chem., https://doi.org/10.1021/ic981137h.

Crawford S E, Lofts S and Liber K 2017 The role of sediment properties and solution $\mathrm{PH}$ in the adsorption of uranium (VI) to freshwater sediments; Environ. Pollut. 220 873-881, https://doi.org/10.1016/j.envpol.2016.10.071.

Cumberland S A, Douglas G, Grice K and Moreau J W 2016 Uranium mobility in organic matter-rich sediments: A review of geological and geochemical processes; Earth-Sci. Rev $\mathbf{1 5 9}$ 160-185, https://doi.org/10.1016/j.earscirev.2016.05.010.

Ding D, Fu P, Li L, Xin X, Hu N and Li G 2014 U(VI) ion adsorption thermodynamics and kinetics from aqueous solution onto raw sodium feldspar and acid-activated sodium feldspar; J. Radioanal. Nucl. Chem. 299(3) 1903-1909, https://doi.org/10.1007/s10967-013-2903-2.

Du Y, Yin Z, Wu H, Li P, Qi W and Wu W 2015 Sorption of $\mathrm{U}(\mathrm{VI})$ on magnetic illite: Effects of $\mathrm{pH}$, ions, humic substances and temperature; J. Radioanal. Nucl. Chem. 304(2) 793-804, https://doi.org/10.1007/s10967-014-3893-4.

Fatima H, Djamel N, Samira A and Mahfoud B 2013 Modelling and adsorption studies of removal uranium(VI) ions on synthesised zeolite NaY; Desalination Water Treat., https://doi.org/10.1080/19443994.2013.769756.

Freimann S and Rahman S 2001 Refinement of the real structures of 2:1 and 3:2 mullite; J. Eur. Ceram. Soc. 21(14) 2453-2461.

Ganesh R, Robinson K G, Chu L, Kucsmas D and Reed G D 1999 Reductive precipitation of uranium by Desulfovibrio Desulfuricans: Evaluation of cocontaminant effects and selective removal; Water Res. 33(16) 3447-3458, https:// doi.org/10.1016/S0043-1354(99)00024-X.

Gao X, Bi M, Shi K, Chai Z and Wu W 2017 Sorption characteristic of uranium(VI) ion onto K-feldspar; Appl. Radiat. Isot. 128 311-317, https://doi.org/10.1016/j. apradiso.2017.07.041. 
Griesser K J, Beran A, Voll D and Schneider H 2008 Boron incorporation into mullite; Mineral. Petrol. 92(3-4) 309-320, https://doi.org/10.1007/s00710-007-0210-8.

Huang Y, Zheng C and Xie C 1998 Study on the preparation and structure of mullite membrane; J. Inorg. Mater. 16(3) $555-558$.

Kulkarni P S 2003 Recovery of uranium(VI) from acidic wastes using Tri-n-octylphosphine oxide and sodium carbonate based liquid membranes; Chem. Eng. J. 92(1-3) 209-214, https://doi.org/10.1016/S1385-8947(02)00255-3.

Li S Y, Xie S B, Zhao C, Zhang Y P, Liu J X and Cai T 2013 Efficiency of adsorption of wastewater containing uranium by fly ash; Adv. Mater. Res. 639-640 1295-1299, https:// doi.org/10.4028/www.scientific.net/AMR.639-640.1295.

Lima A T, Ottosen L M and Ribeiro A B 2012 Assessing fly ash treatment: Remediation and stabilization of heavy metals; J. Environ. Manage. 95(Suppl) S110-S115, https://doi.org/10.1016/j.jenvman.2010.11.009.

Mellah A, Chegrouche S and Barkat M 2006 The removal of uranium(VI) from aqueous solutions onto activated carbon: Kinetic and thermodynamic investigations; J. Colloid Interface Sci. 296(2) 434-441, https://doi.org/10.1016/j. jcis.2005.09.045.

Michard P, Guibal E, Vincent T and Le Cloirec P 1996 Sorption and desorption of uranyl ions by silica gel: $\mathrm{pH}$, particle size and porosity effects; Microporous Mater. 5(5) 309-324, https://doi.org/10.1016/0927-6513(95)00067-4.

Monnet A, Gabriel S and Percebois J 2017 Long-term availability of global uranium resources; Resour. Policy 53 394-407, https://doi.org/10.1016/j.resourpol.2017.07. 008 .

Nekhunguni P M, Tavengwa N T and Tutu H 2017 Sorption of uranium(VI) onto hydrous ferric oxide-modified zeolite: Assessment of the effect of $\mathrm{pH}$, contact time, temperature, selected cations and anions on sorbent interactions; $J$. Environ. Manage. 204 571-582, https://doi.org/10.1016/j. jenvman.2017.09.034.

Pu Y, Yang X, Zheng H, Wang D, Su Y and He J 2013 Adsorption and desorption of thallium(I) on multiwalled carbon nanotubes; Chem. Eng. J. 219 403-410, https://doi. org/10.1016/j.cej.2013.01.025.

Reinoso-Maset E and Ly J 2016 Study of uranium(VI) and radium(II) sorption at trace level on kaolinite using a multisite ion exchange model; J. Environ. Radioact. 157 136-148. https://doi.org/10.1016/j.jenvrad.2016.03.014.

Ren X, Wang S, Yang S and Li J 2010 Influence of contact time, pH, soil humic/fulvic acids, ionic strength and temperature on sorption of $\mathrm{U}(\mathrm{VI})$ onto MX-80 bentonite;
J. Radioanal. Nucl. Chem. 283(1) 253-259, https://doi. org/10.1007/s10967-009-0323-0.

Rüscher C H 1996 Phonon spectra of 2:1 mullite in infrared and Raman experiments; Phys. Chem. Min. 50-55, https:// doi.org/10.1007/BF00202993.

Schneider H, Schreuer J and Hildmann B 2008 Structure and properties of mullite - A review; J. Eur. Ceram. Soc. 28(2) 329-344, https://doi.org/10.1016/j.jeurceramsoc.2007.03. 017.

Singh S K, Tripathi S C and Singh D K 2010 Studies on the separation and recovery of uranium from phosphoric acid medium using a synergistic mixture of (2-ethylhexyl)phosphonic acid mono 2-ethyl hexyl ester (PC-88A) and Tri-noctylphosphine oxide (TOPO); Separation Sci. Tehnol. 45(6) 824-831, https://doi.org/10.1080/0149639100360 7498.

Suzuki Y, Awano M, Kondo N and Ohji T $2001 \mathrm{CH}_{4}$-sensing of porous $\mathrm{CaZrO}_{3} / \mathrm{MgO}$ composites with three-dimensional; J. Ceram. Soc. Japan 109(1) 79-81.

Sylwester E R, Hudson E A and Allen P G 2000 The structure of uranium(VI) sorption complexes on silica, alumina, and montmorillonite; Geochim. Cosmochim. Acta 64(14) 24312438, https://doi.org/10.1016/S0016-7037(00)00376-8.

Vaaramaa K, Pulli S and Lehto J 2000 Effects of pH and uranium concentration on the removal of uranium from drinking water by ion exchange; Radiochim. Acta $\mathbf{8 8 ( 1 2 )}$ 845-849, https://doi.org/10.1524/ract.2000.88.12.845.

Vassilev S V, Menendez R, Alvarez D, Diaz-Somoano M and Martinez-Tarazona M R 2003 Phase-mineral and chemical composition of coal fly ashes as a basis for their multicomponent utilization. 1. Characterization of feed coals and fly ashes; Fuel 82(14) 1793-1811, https://doi.org/10.1016/ S0016-2361(03)00123-6.

Voll D, Lengauer C, Beran A and Schneider H 2001 Infrared band assignment and structural refinement of Al-Si, Al-Ge, and Ga-Ge mullites; Eur. J. Min. 13(3) 591-604, https:// doi.org/10.1127/0935-1221/2001/0013-0591.

Zhao G, Rao P and Lu M 2006 Research and application of mullite and porous mullite; China Ceram. 42(9) 13-17.

Zheng H, Liu D, Zheng Y, Liang S and Liu Z 2009 Sorption isotherm and kinetic modeling of aniline on Cr-bentonite; J. Hazards Mater. 167(1-3) 141-147, https://doi.org/10. 1016/j.jhazmat.2008.12.093.

Zhu W, Liu Z, Chen L and Dong Y 2011 Sorption of uranium(VI) on Na-attapulgite as a function of contact time, solid content, $\mathrm{pH}$, ionic strength, temperature and humic acid; J. Radioanal. Nucl. Chem. 289(3) 781-788, https://doi.org/10.1007/s10967-011-1129-4.

Corresponding editor: Pulak Sengupta 